\title{
Data Collection and Distribution in Nigerian Higher Institutions: Problems and Way Forward
}

\author{
Ogunode Niyi Jacob, \\ University of Abuja, Nigeria \\ Email id: Ogunodejacob@gmail.com
}

\begin{abstract}
Higher institutions in Nigeria are facing many challenges. One of such challenges is lack of creditable data to plan and to take decisions on development of the institutions. This paper is aim to discuss the problems of data collection and distribution in the Nigerian higher institutions. Secondary data were employed to discuss the various points raised in the paper. The secondary data were sourced from both hard ware and software resources. The paper identified inadequate funding, inadequate working materials, shortage of professional data experts, poor capacity development of data mangers and inadequate infrastructural facilities as the problems preventing effective data collection and distribution in the Nigerian higher institutions. To address these problems, the paper recommended that the government should increase the funding of higher institutions, more professional data mangers should be employed, adequate working tools should be provided, training and retraining programme should be constantly provided for data mangers and school administrators should provide all infrastructural facilities needed by units and departments handling data management in the various higher institutions in the country.
\end{abstract}

Keywords: Inadequate, Infrastructural facilities, Public, Universities

\subsection{INTRODUCTION}

The National Policy on Education (FGN, 2004), defines Higher Education as the Post -Secondary Section of the National education system, which is given of Universities, Polytechnics and Colleges of Technology including courses as are given by the Colleges of Education, Advanced Teachers Training colleges, Correspondence Colleges and such institutions as may be allied to them. The role of higher education as essential to national development cannot be over emphasized. This is due to the contribution of higher education in producing higher-level skills and competencies as essential to national development particularly in the context of globalization and the shift towards knowledge economies. For these reasons, countries all over the world, Nigeria inclusive are giving higher education the needed policy attention.UNESCO, (2003) submitted that Higher education includes all types of study, training or trainings for research at post-secondary level, provided by the universities or other educational establishments that are approved as institutions of higher education by competent state authorities). Johnstone (2006) observed that higher education as an agent of change, national growth and instrument for the realization of collective aspiration should contribute to the development of the entire education system through teacher education, curriculum development and educational research thereby providing the crucial mass skills and educated populace needed by any country to ensure genuine endogenous sustainable development. 
Adeyemi(2001), viewed Higher Education as a system which embraces much of the country's research capacity and reproduces majority of the skilled professionals that are required in the labour market. The objective of higher education include:the acquisition, development and inculcation of the proper value orientation for the survival of the individual and societies; the development of the intellectual capacities of individuals to understand and appreciate environment; the acquisition of both physical and intellectual skills which will enable individuals to develop into useful members of the community; and the acquisition of an overview of the local and external environments (FGN, 2004). The National Policy on Education again stated that higher educational institutions should pursue these goals through: teaching, research, the dissemination of existing and new information, the pursuit of service to the community; and by being a store- house knowledge (FGN, 2004).

For effective data collection and distribution in the higher institutions in Nigeria, the Nigerian government established different commissions to collected and distribute higher institutions data in the country. These commissions include: National Universities Commission to collect universities data for effective administration of the universities in Nigeria. National Board for Technical Education was established to also collect and analysis the data from all polytechnics in the country while National Commission for Colleges of Education handles the data management of Colleges of education in Nigeria. All this commissions supervise all higher institutions in Nigeria.

To ensure effective data administration and management in the higher institutions, the various regulatory organizations directed the universities, college of education and the polytechnics to establish units and departments to handle data collection, analysis and dissemination information within the institutions and the ministry of education. At the universities, the academic planning unit and Management Information system (MIS) units were established in Nigerian University system

Data is very important to the realization of goals and programme of higher institutions. Data is needed to plan the higher institutions. The Executive Secretary of National Universities Commission said that for the Nigerian University System (NUS) to be respected globally, it must live above board by managing an effective and reliable information system that would guarantee accurate, reliable and timely data that could be used in advising government on issues of national planning. He observed that without accurate data, effective and strategic planning would not only be difficult for the university but also for the government. He said that as Ivory Towers, Universities were expected to have adequate and reliable information across all variables such as total number of students enrolment; total number of students by programme; faculty; gender; age; mode of entry into the university; Local Government of origin; State of origin; nationality; geo-political zone; distribution in term of PhD, Masters, PGD programmes and students (NUC,2016). It is unfortunate that data on higher education in Nigeria are not timely generated and made available. Dominic, Segun\&Jide (2016) observed that timely and reliable data are fundamental to planning and management in education especially in monitoring educational developments. According to ESSPIN ([21]) there is currently a lack of timely, reliable data on education on which to effect basic decisions at all levels in the system. The unavailability of data is affecting the progress and development of Nigerian educational sector because policy makers, school administrators, school managers and international institutions cannot access current data to plan, design policies and support the development of education in the country. This paper therefore examines the problems of data collection and distribution in the Nigerian higher institutions

\subsection{Concept of Data}

Data is an unorganized set of numbers, undefined and meaningless. Data is a set of facts collected from a particular examination that must be further processed to be meaningful for planning and for making decision. Advanced learner dictionary of current English (2008) viewed data as information, especially facts collected for examination and consideration made and then used to help in decision making. It 
could be information in an electronic form that can be stored and processed by a computer to provide meaningful information. Borisade (2002) sees data as a set of raw or unrefined values collected for the response variables for which each of the elements belongs to the sample.

Data collection is the process of identifying, collecting and evaluating information on different subject systematically. It provides the answers to the actual question and assess the results.Data Dissemination is the act of making available facts and processed information for public consumption.

Borisade(2012) observed that there are two major types of data. These are the primary data and the secondary data. Primary data are those data that are collected during the course of doing experiments in an experimental research, but in case of descriptive type, we can obtain primary data either through observation or through direct communication with respondents in one form or through personal interviews. In other words, primary data can be collected using different methods. These include, observation method, interview, questionnaire through schedule in some cases, warrant cards (postal card) pantry audits etc. On the other hand, secondary data are data that are already available. That is data that have already been collected and analyzed by someone else. This includes, published data or unpublished data, such as newspaper, government books, magazines reports of various associations, historical document from archives or museum. Others may include diaries, letters, unpublished biographies and auto-biographies, private/public individual and organization.

Dominic, Segun\&Jide (2016) submits that the success of any system of education is hinged on proper planning through the use of data. The need for data based policy making in national educational sector is more now than before particularly with the current revolution in information and communications technology which has made the world to become a global village. The inconsistencies observed in most educational sector decisions might make one infer that these decisions were based on incomplete information, intuition or rule of the thumb. Education data, like other social data, facilitates planning and constitute invaluable inputs for computing important social indicators which are used to monitor trends in the quality leading to improvement in policy decisions of the sector and better impact. Discovery of where gaps are in education or where we need to concentrate more energy are all product of use and evaluation of data. Unfortunately, Nigeria's education system is in dire need of data based policy formulation that will restore the ailing system. It is the data based policy decision making in education that will ensure better returns on educational investment and stimulate economic growth and national development.Data based policy making ensures accountability in the management of education. Poor planning and non-use of data for policy decision-making is predominant in the educational sector and empirical information/ reports are rare.

\subsection{Level of Data Availability in Nigerian Higher Institutions}

The Nigerian educational system is faced with the problem of shortage of current and reliable data for effective administration and management. The problems is more pronounced in the higher institutions in the country. The Nigerian higher institution is made up of the universities, Colleges of education and polytechnic education.

At the universities, the National Commission Universities (NUC) Boss, He said, "I was totally disturbed that we could not lay our hand on a verifiable statistics that would have to help us with our plans for our universities. That made me to spend my first year as NUC boss studying some obvious inaccurate statistics being brandished in different quarters regarding the current situation in our Nigerian universities (NUC, 2018).

At the Colleges of education, Moja, (2000) observed that any analysis of the Nigerian education sector include Colleges of education is particularly challenging due to the lack of adequate data. Most of the literature available only provides information up to the midnineties. Data available was primarily for the eighties or early nineties. He went further to observed that data on the education system have not been 
collected in a timely manner or processed in a way that is adequate for planning. The system has thus suffered from lack of adequate planning for the implementation of the policies that are vital to improved quality and expansion (Moja, 2000).

At the polytechnic education, NEEDS, (2014) submitted that it was challenging to obtain data with current statistics for the assessment mainly due to the fact that current data on the education sector was generally not available in the public domain. The assessment therefore relied on available data, some of which was more than three years old and had not been updated at the time of the study. The assessment was also limited by the reluctance of government officials to release data or respond to surveys and inquiries despite several follow-up visits, contacts and reminders. Also, another major limitation of the report is the non-availability of qualitative data on polytechnic education. Though contacted, the Executive Secretary of the NBTE, who is the head of government parastatal in charge of polytechnic education in Nigeria, could not participate in the key information interview used to gather qualitative data for the assessment.

Ogunode (2021) identified: lack of data/information, inadequate funding of planning, inadequate educational planners, , lack of planning materials, political influence, political instability, policies instability, corruption, poor capacity development of educational planners and lack of political will to support planning of education as the challenges preventing effective planning of education in Nigeria. Ololube, (2013) submitted that one of the most difficult challenges that educational planners face is the issues of inaccurate statistical data. The quality of technical planning is in most cases inhibited by statistical deficiencies and inaccurate data. Nigerian education systems has failed to effectively plan because of lack of accurate data, which is because of the use of mediocre to prepare data for use in the planning and forecasting processes. Noun (2009) argued that the process of educational planning in Nigeria is also hampered by the critical problem of inadequate statistical and demographic data.

Victoria \&Owuama (2016) conducted a study that aimed at determining the constraints to planning and implementation of higher education programmes was carried out, with emphasis on the six higher institutions in Rivers State. The result of the study revealed among others that planning without accurate statistical data, inadequacy of funds, political influence, and misappropriation of funds and shortage of qualified manpower were major constraints. The findings also revealed that there were significant difference between male and female unit heads on the perception of constraints to planning and implementation of higher education programmes

Ogunode (2021) opined that inadequate data is another problem preventing effective educational planning in Nigeria, There is shortage of educational data on all the forms of educational institutions in the country. There is lack of data on the early child education programme, there is shortage of data on primary school education, there is inadequate data on secondary school education and there is lack of data on the higher education in Nigeria. The inability of the government agencies to generate current and reliable data for all the forms of education in affecting the planning of education in Nigeria.

Zafar, Mohammad \&Yasir (2011) opined that the availability of accurate, valid, reliable, and timely information is a pre-requisite for planning and management in any sector. Educational planning and management is no exception, it requires the availability and use of a diverse set of data for effective planning and successful management. To plan and manage in education sector, the following information should be available: demographic information, educational statistics, budget allocations for education sector and Human resource in education sector. Data helps education planners and decisionmakers to know the structure and distribution of the population at a given time frame, as well as how it has changed in recent years. In other words, educational planning and management cannot be divorced from considerations about dynamics of population (i.e., its growth and change), as it deals with a 'target 
population' which is constantly changing in number, age and sex composition, and geographic distribution (Zafar, Mohammad \&Yasir (2011).

Dominic, Segun\&Jide (2016) Data for Nigeria's educational policies are from census data (National Population Commission), National Bureau of statistics, Federal Ministry of Education. These sources may not be having reliable demographic data essentially needed for decision making. Data are essential tools for educational decision-making but most of the sources of data available are either extrapolated or based on census data which are not accurate. Without a reliable baseline demographic data, it becomes difficult to plan.

Effective data management in the higher institutions will lead to: effective planning of higher education, effective implementation of higher education, realization of the objective of higher education, reduction of wastage in higher education, effective decision making and attraction of international donors.

\subsection{Problems Preventing Effective Data Collection and Distribution in Nigerian Higher Institutions}

The following are the problems preventing effective data collection and distribution in the Nigerian higher institutions: inadequate funding, inadequate working materials, shortage of professional data experts, poor capacity development of data mangers and inadequate infrastructural facilities

\subsection{Inadequate Funding}

Inadequate funding is a major problem responsible for ineffective data collection and distribution in the Nigerian higher institutions in Nigeria. The funds allocated for the administration of data collection, storage, management and dissemination is not adequate in many higher institution in the country. The funds released for the administration of higher institution in Nigeria is not adequate. The shortage of funds is responsible for poor management of data in the various public higher institutions in the country.AdamuAdamu listed some of the challenges facing data collection to include inadequate funding, poor capacity building, inadequate infrastructural development and inadequate collaboration at various levels (Prnigeria, 2016).Ogunode\&Abubakar (2021) observed that one major problem affecting the administration of higher education in Nigeria is underfunding. Inadequate funding is a challenge to realization of the objective of education in Nigeria. The funding style adopted by the government for the funding of tertiary education is not stable and is affecting the development and survival of the university system. Higher institutions cannot carry out their cardinal function of teaching, researching and provision of community services. The higher institutions find it difficult to funds the sub-units in the system effectively to discharge their functions. The higher institutions especially the university system is designed to work with many sub-units. Among these units academic planning unit, Udida, Bassey, Udofia, \&Egbona (2009) observes that the major issue in educational development is shortage of funds. One of the most serious problems threatening the survival of the educational systems is that of dwindling level of public funding in the face of rising demands and hence rising cost of higher education. This shortage of funds affects job performance and the growth of the institution. Higher educational institutions cannot perform optimally without funding. This situation calls for increased fund initiative from both the government and educational stakeholders so as to sustain the tempo and growth of education industry. The inability of the Nigerian government to objectively accept and implement the $26 \%$ funding formula for education recommended by the UNESCO impact negatively on the performance and sustainability of higher education. Thus, it has become obvious that Nigeria's neglect of the funding formula is detrimental to higher educational institution performance and development aspiration as quality performance is the veritable instrument for sustenance of education system. This neglect has further precipitated crises in the entire higher educational systems as effective teaching, research and service are no longer taking place seriously. 


\subsection{Inadequate Working Materials}

Inadequate working materials is a very big challenge preventing effective data collection and distribution in the public higher institutions in Nigeria. Many departments and units handling data collection and distributions in the various higher institutions in the country do not have adequate working materials in their offices and tis is affecting the smooth administration of data collection in the various higher institutions in the country.Ogunode\&Abubakar (2021) submits that lack of adequate working tools is another problem facing the majority of Nigerian universities. Working tools or office equipment like Stapler, Eraser, Push-pin, Drawing pin (U.K)/ Thumbtack (U.S), Paper clip, Rubber stamp, Highlighter, Fountain pen Pencil, Marker, Ballpoint, Bulldog clip, Tape dispenser, Pencil sharpener, Label, Calculator, Glue, Scissors, Sticky notes, 4A Paper, Notebook, Envelope, Clipboard, Monitor, Computer, Keyboard, Folder, Fax, Filing cabinet, Telephone, Swivel chair, Desk, Wastebasket, printer and calculators are inadequate in many students' affairs units across the various universities in the country.

\subsection{Shortage of Professional Data Experts}

Another problem hindering effective administration of data collection and distribution in the Nigerian higher institutions is the problem of shortage of professional data experts. There is shortage of professional data experts in majorities of the units and departments established for data management in the various higher institutions in the country and this is directly affecting data collection and distribution in the higher institutions. Nkechi, Martins, \& Lydia (2019) submitted that challenges preventing effective big data administration include lack of personnel and experts for programming and modelling, lack of electric power, poor access to internet, lack of awareness among experts and professionals. Similarly, Godwin, (2016) outlined many reasons for poor statistics in national development, the application of statistical techniques in the day-to-day running of government business is still very low to include: there is inadequate manpower with statistical training, literacy rate in the country is still very low; cultures of the different nationalities that make up Nigeria do not promote record-keeping; there has not been sufficient political commitment to the promotion of statistical education, generally; and , lack of accountability among government officials which makes them regard any form of statistical inquiry as a kind of "audit investigation".

\subsection{Poor Capacity Development of Data Mangers}

Poor capacity development of data mangers and officers is another big problem militating against effective data collection and distribution in the higher institutions in the country. Dominic, Segun\&Jide (2016) the problems of data collection are many, such as corruption, low skilled manpower, unreliable demographic data, non-availability of reliable educational data, politics, multiple and proliferation of educational policies. Bernadette \&Ukaegbu, (2017) carried out a study as cited by Ogunode\&Abubakar (2021) on impact of poor implementation of welfare policies on training and development on the performance of academic staff in selected federal Universities in South-South Nigeria was carried out to examine the extent to which poor implementation of welfare policies on training and development impacts on the performance of workers in the selected Federal universities in South-South Nigeria. The study discovered that, whereas there are good welfare policy statements in the study area, the level of implementation of these policies were poor. Furthermore, over $90 \%$ of the respondents insisted that full implementation of welfare policies would have positive impact on workers ${ }^{\text {ee }}$ performance to a very large extent. The results further indicated that there have been very few in-house and outside training programmes in the study area. A total of $87 \%$ of respondents agreed that poor level of implementation of welfare policies on training and development is a source of discouragement which have negatively affected academic performance of both teaching and non-teaching staff and have led to poor service delivery in our Universities. To Asiyai and Oghuvbu (2009), the lack of staff development programmes 
accounted for the decline in quality of tertiary education in Nigeria while Adeogun, (2006) observed that an employee who is not trained and exposed to continuous retraining in the modern methods and new discoveries in his or her field will soon become irrelevant to the organization.

\subsection{Inadequate Infrastructural Facilities}

Inadequate infrastructural facilities is another problem hindering effective collection and distribution of data in the higher institutions in the country. Infrastructural facilities like stable electricity, stable internet services, computers systems and laptop are not available in the qualities and qualities that will support effective data collection and distribution. Godwin, (2016) opined that the main problems militating against an efficient statistical education programme in the country revolve around insufficient number of well-qualified statistics teachers at all levels, as well as inadequate facilities in schools, colleges and universities. Udeme (2017) who listed other factors that account for inaccurate data to include poor technological advancement, poor infrastructure, poor funding, shortage of manpower, and ineffective supervision.Nkechi, Martins, \& Lydia (2019) also observed that the major problem in generating and processing assessment big data from the experts' opinion is low level of infrastructural development, low awareness on the need/advantages of assessment big data, followed by security issues in contracting data and technical knowhow and lack of trained ICT officers.

\subsection{Way Forward}

To address these problems, the paper recommended that the government should increase the funding of higher institutions, more professional data mangers should be employed, adequate working tools should be provided, training and retraining programme should be constantly provided for data mangers and school administrators should provide all infrastructural facilities

a) The government should increase the funding of higher institutions in the country;

b) The public higher institutions in the country should employ more professional data officers and deploy them to units handling data collection and distributions;

c) The school administrators should ensure data collection officers working in the various units and departments in the schools should be constantly trained to boost their data collection capacity. Training on forecasting, projection and planning methods should be emphasized.

d) More infrastructural facilities should be provided in all public higher institutions in Nigeria such as stable electricity and stable internet services. This will aid the data collection officers to collect and distribute

e) Working materials should be provided for all the data collection officers in the public higher institutions in Nigeria. Working materials like calculators, laptops, computer system etc

\subsection{CONCLUSION}

The place of data in the realization of the higher education goals in Nigeria cannot understated because data is a management tools for planning and taking decisions for effective administration.

Data generation, collection and dissemination is a major problem facing the higher institutions in Nigeria. This paper identified inadequate funding, inadequate working materials, shortage of professional data experts, poor capacity development of data mangers and inadequate infrastructural facilities as the problems preventing effective data collection and dissemination in the Nigerian higher institutions. To address these problems, the paper recommended that the government should increase the funding of higher institutions, more professional data mangers should be employed, adequate working tools should be provided, training and retraining programme should be constantly provided for 
data mangers and school administrators should provide all infrastructural facilities needed by units and departments handling data management in the various higher institutions in the country.

\section{REFERENCES}

1. Asiyai RI and Oghuvbu EP (2009) An empirical analysis of the causes and possible solutions to decline in quality of tertiary education in Delta state, Nigeria. Journal of Sociology and Education in Africa 8(2):1-1 2.

2. Borisade, F. T.(2002). Introductory statistics and vocamentric. Integrity Publishers, Ibadan

3. Borisade F. T. (2012) Roles and Problems of Data Collection for Students' Evaluation At The Junior Secondary School In Nigeria. Journal Of Research In Education And Society; Volume 3, Number 1,pp-163

4. Alao, B.S. (2010) The Impact of Training and Development on Employees Performance: A Case study of Nigerian Bottling Company. A B.Sc. Research Project: Faculty of Business and Social Sciences, University of Ilorin 7.

5. Bernadette C.N \&Ukaegbu, O (2017)Impact of Poor Implementation of Welfare Policies on Training and Development on the Performance of Academic Staff in Selected Federal Universities in South-South Nigeria. International Journal of Scientific Research and Management (IJSRM) Volume(5)Issue (12)|Pages 7718-7729

6. Dominic A, Segun J,\&Jide I (2016)The Use Of Data In Policy-Making In Nigeria's Educational Sector: Implications For NationalDevelopment

7. Godwin, E,. O. (2016) Statistical Education In Nigeria - Problems And Prospects

8. Johnstone Bruce (2006). Financing higher education: Cost sharing in international perspective. Boston College Center for International Higher Education. Boston. Sense Publishers.

9. Moja, T. (2000). Nigeria Education Sector Analysis: An Analytical Synthesis of Performance and Main Issues. Report produced for the World Bank.

10. Noun (2009) Concepts and Theories of Educational Administration and Planning EDA 811

11. NEEDS, (2014). Needs assessment in the Nigerian education sector. International organization for migration, Abuja, Nigeria.

12. Nkechi P-M, Martins N,. E, Lydia I,. E (2019)Assessment big data in Nigeria: Identification, generation and processing in the opinion of the experts.International Journal of Evaluation and Research in Education (IJERE)Vol. 9, No. 2, June 2020, pp. 345 351

13. NUC (2018) NUC says there are 1.9m students in Nigerian universities.

14. NUC (2016) Accurate Data Essential for National Development (NUC To Publish Statistical Digest-Prof.Rasheed).https://www.nuc.edu.ng/accurate-data-essential-for-national-developmentnuc-to-publish-statistical-digest-prof-rasheed/

15. Moja, T. (2000). Nigeria Education Sector Analysis: An Analytical Synthesis of Performance and Main Issues. Report produced for the World Bank.

16. Ololube, N. P. (2013) The Problems and Approaches to Educational Planning in Nigeria: A Theoretical Observation. Mediterranean Journal of Social Sciences MCSER Publishing, RomeItaly Vol 4 No 12

17. Ogunode, N,.J \&Abubakar M. (2021) Students' Affairs Units In Nigerian Universities: Challenges And The Way Forward.European Journal of Humanities And Educational Advancements (EJHEA), Vol. 2 No. 3,pp-11-19

18. Ogunode, N,J (2021) Challenges Preventing Effective Planning of Education in Nigeria and the Ways Forward,Central Asian Journal of Theoretical and Applied Science, Vol (2) 2, pp- 30-39

19. Victoria C. O, \&Owuama D, N (2016)Constraints in planning and implementation of higher education programmes in rivers nigeria European Scientific Journal

20. UNESCO (2003). News Letter. Education Section, 5. Retrieved from 
http://www.upo.unesco.org (April 102012)

21. Udeme U (2017) Planning Nigerian Education: Problems, Issues, and Proposed Solutions.publication at: https://www.researchgate.net/publication/316682135

22. Zafar I. M, Mohammad N, A, \&Yasir I,. (2011)National Education Management Information

SystemAcademy of Educational Planning and Management Ministry of Professional \& Technical Training, Islamabad 